\section{A Compensatory Growth like Analysis of Common Carp Cyprinus carpio L. among Different Combinations in Full Diallel Crossing}

\author{
Shengyan Su, Zaijie Dong*, Wenbin Zhu, Lanmei Wang and Jianjun Fu \\ Key Laboratory of Freshwater Fisheries and Germplasm Resources Utilization, \\ Ministry of Agriculture, Freshwater Fisheries Research Center, Chinese Academy of \\ Fishery Sciences, Wuxi, 214081, China
}

\begin{abstract}
A B S T R A C T
A novel method was produced to explore the catch-up like growth from diallel cross-breeding due to its similarity with high growth speed in the later period for common carp Cyprinus carpio L cross-breeding. A compensatory index matrix for $3 \times 3$ full diallel cross combinations used for selection was built to investigate compensatory like growth of each combination. $\mathrm{Yes} / \mathrm{No}(\mathrm{Y} / \mathrm{N})$ effect was determined for specific combination dyads, which there were significant differences in body weight at tagging, but no difference in body weight at harvesting. Among the 36 dyads, 7 had an YN response (19.4\%). When the YN effect had a fixed accumulated value, the value reflected its compensatory like growth degree, i.e., no catch-up like growth in one group means no $\mathrm{YN}$ effect in one group can be detected. Heilongjiang carp $\widehat{\delta}$ $\times$ Jian carp $+(\mathrm{Yj})$ combination had the highest catch-up like growth degree and the Heilongjiang carp $\widehat{\delta}$ $\times$ Heilongjiang carp + (Yy) combination had no compensatory like growth. Reference standard was set as arithmetic progression in 5\% each step for the whole group (e.g. $5 \%, 10 \%, 15 \%$, etc.) Compared the harvesting weight and weight gain, significant differences were found between non-compensatory like growth and compensatory like growth group on all levels except the $25 \%$ level. Particularly, the $35 \%$ level had the biggest compensatory like growth. Body shape changed during the compensatory like growth process. This study shows that compensatory like growth of body weight during the cross-breeding can be detected and quantified.
\end{abstract}

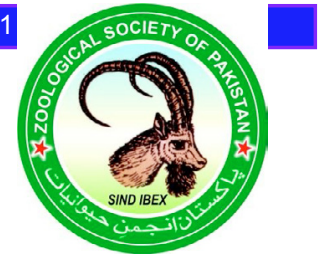

CrossMark

Article Information
Received 08 February 2017
Revised 20 March 2017
Accepted 31 March 2017
Available online 14 November 2017
Authors' Contribution
SYS worked out the design, analyzed
data and wrote the article. DZJ, ZWB,
FJJ and WLM conducted the study
and collected the data.
Key words
Cyprinus carpio L., Compensatory like
growth, Full diallel cross, YN effect.

\section{INTRODUCTION}

$\mathrm{C}$ ompensatory growth is a physiological process that induces accelerated growth and takes place when favorable conditions are restored after a period of growth depression (Ali et al., 2000). It can be quantified by a compensatory index that is calculated as the ratio of the difference between weight variation at the end of restricted and compensatory growth periods, respectively, relative to the variation at the end of the restricted growth alone (Hornick et al., 2000). The magnitude of growth compensation ranges from overcompensation, to full, partial or no compensation, according to the biomass reached by fish under restriction conditions compared to fish under no restriction (Ryan, 1990; Lippens et al., 2002). Su et al. (2011) had the growth experiment for cross breeding of Cyprinus carpio L.

\footnotetext{
Corresponding author: dongzj@ffrc.cn 0030-9923/2017/0006-2123 \$9.00/0

Copyright 2017 Zoological Society of Pakistan
}

without any environment related restriction condition related to growth depression. Thus growth different observed between different combination can be attributed by the genetic factor regarded as a restriction factor.

Compensatory growth in fish is not only of theoretical interest, but also has applications in the design of feeding schedules that improve growth rates and reduce costs (Chaoui et al., 2006; Bavčević et al., 2010; Khan and Abidi, 2010). In 2015, the total production of Chinese freshwater fish represented 27150075 tons, of which, common carp, Cyprinus carpio L., accounted for $12.37 \%(3357962$ tons). Thus, common carp is a major species in Chinese aquaculture production. In order to evaluate the possible benefits of compensatory like growth in cross breeding, it is necessary to understand the dynamics change underlying

\footnotetext{
Abbreviations

Yj Heilongjiang carp $\partial^{\lambda} \times J_{i a n}$ carp + ; Yy Heilongjiang carp $\delta \times$ Heilongjiang carp $\odot$; Yh Heilongjiang carp $\delta \times$ Huanghe carp $\odot$; Jh Jian carp $\delta \times$ Huanghe carp $\odot$; Jj Jian carp $\delta^{\lambda} \times$ Jian carp + ; Jy Jian carp $\delta \times$ Heilongjiang carp $\mathrm{q} ; \mathrm{Hh}$ Huanghe carp $\delta \times$ Huanghe carp $\%$; Hj Huanghe carp $\hat{\partial} \times$ Jian carp $q$; Hy Huanghe carp $\hat{\partial} \times$ Heilongjiang carp $q$.
} 
this genetic trait. Here, we present an experiment that analyzed the effects of compensatory like growth on body weight and other growth traits in a $3 \times 3$ full diallel cross between three common carp strains ( $\mathrm{Su}$ et al., 2011). The compensatory index matrix for whole groups was constructed in order to understand the compensatory like growth of each combination dyad. In addition, the relationships between groups of fish with a given cross combination and compensatory like growth were determined using defined $\mathrm{Y} / \mathrm{N}$ effect and compensatory like growth degree method.

\section{MATERIALS AND METHODS}

\section{Animals stocks, mating design and rearing of larvae}

Three varieties of common carps were obtained from the station of the Freshwater Fisheries Research Center

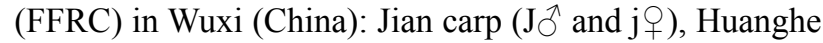

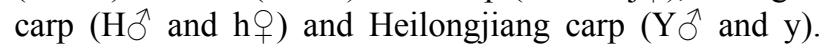
Three full diallel crosses were carried out involving these varieties with 10 brood fish ( 5 males and 5 females, averaging $1200 \mathrm{~g}$ ) in each cross (except the purebreds that each had one full sib family). For each stock, females were stimulated for spawning with hormone, and fertilized with the milt from matched male brooder. The fertilized eggs were transferred to labeled hatching hapas, which were setup in rows within a concrete tank. One week later, larvaes were transferred to separated nursery hapas.

\section{Tagging and production environment}

Breeding and nursery were conducted in fine-mesh hapas inside a concrete tank. Two rows of hapas (nylon net cloth) were installed with $40 \mathrm{~cm}$ passage for inspection and feeding. A total number of 1,650 fish were stocked and distributed in 33 hapas with 5 replications for each crossbred and 1 replication for each purebred. The size of the hapas was $120 \mathrm{~cm}$ (length) $\times 80 \mathrm{~cm}$ (width) $\times 100$ $\mathrm{cm}$ (depth) and each one corresponded to a single cross combination. The tanks were supplied with filtered well water and equipped with air stones for continuous aeration. Throughout the experiment, the dissolved oxygen ranged from 3.8 to $8.6 \mathrm{mg} / \mathrm{L}, \mathrm{pH}$ from 7.2 to 8.5 and temperature from $18^{\circ} \mathrm{C}$ to $20^{\circ} \mathrm{C}(19.40 \pm 0.02)$ and the fish were fed to satiation. After about three months of ad libitum feeding (all fish were fed by 5\% of their body weight), 50 fish were randomly sampled from each family offspring and tagged individually with passive integrated transponder tags (PIT) produced by Biomark. Tagged fish were reared in one pond after temporary culture (used to be cared for them due to tagging operation) for 3 days. Fish were fed a commercial feed with $30 \%$ of protein under the water environment illustrated above.
Animal welfare and experimental procedures were carried out in accordance with the Guide for the Care and Use of Laboratory Animals, and were approved by the animal ethics committee of Chinese Academy of Fishery Sciences. Clove oil was used as anesthetics (Velisek et al., 2005) which limit pain during the PIT tagging process. In the following step, all tagging fish were disinfected and strengthened nutrition.

For each cross combination, spawning time, family identification (ID), body weight (g), body length (Standard length, $\mathrm{mm})$, body width $(\mathrm{mm})$, and body depth $(\mathrm{mm})$ were recorded at the time of tagging (also named tagging weight, tagging length, tagging width, tagging depth), which corresponds to the first growth phase. At harvest, the above growth performance of each individual (also named harvesting weight, harvesting length, harvesting width, harvesting depth) were recorded again to analyze the second growth phase lasting 17 months, which corresponds to the period between tagging and harvesting.

Compensatory like growth analysis method used in common carp breeding

The framework of compensatory like growth analysis method used in common carp breeding was displayed in Figure 1 . There were 36 combination dyads (a combination dyad: also called a combination pair, $9 * 8 / 2,72$ if consider the order) created by the 9 cross combinations (6 crossbreds and 3 purebreds), which were reared without any restrictions. In every combination dyad, each cross combination can be viewed either as a control (base line relative to the weight variation) or a weight variation with respect to the control. Two growth phases were defined as restricted (spawning to tagging-genetic restriction factor, in this process, except for genetic background for every individual, the whole individuals within family were reared in the same condition. So the body weight difference observed in one dyad from genetic restricted factor) and compensatory like growth periods (tagging to harvesting, in this process, all individuals were reared in one pond without any different condition, so the motivation of compensatory like growth also comes from the genetic factor). If there is a combination dyad presenting a significant body weight differential during the first growth phase (spawning to tagging) due to genetic restriction factor, it may not show any variation during the second growth stage (tagging to harvesting). Such combination dyad above with the change in the growth pattern (compensatory like growth) was considered to have a $\mathrm{Y} / \mathrm{N}$ response. The total number of YN effects for a given cross combination (one of the 9 breeding combinations) can be calculated. Note that there are at most $9 \mathrm{YN}$ effects for a given cross combination (from 0 to 8 ). A compensatory index was also quantified 
for a restricted catch up like growth pattern as reported by Hornick et al. (2000). Thus the compensatory like growth levels for every combination dyad were also determined by this index size.

The degree of compensatory like growth for each cross combination was evaluated by the number of $\mathrm{Y} / \mathrm{N}$ responses determined for all the combination dyads within a cross combination. Regarding the 9 dyad combinations as $100 \%$ (the number of YN answers ranged from 0 to 8 , total number as $100 \%$ is 9), we can express the number of $\mathrm{YN}$ answers in percentage and determine whether it is above a certain class level in steps of 5\% (classes 5\%, 10\%, 15\%, etc.). Thus all cross combinations were classified into different class levels, each having a fixed value ( 0 or 1$)$ at a given level. If the no cross combination can has 1 value in the higher percentage, such percentage can be regarded as the threshold value. Summation of these values establishes final compensatory like growth magnitude for each given cross combination. Furthermore, the compensatory effect on growth performance was estimated based on these classified variables. The study focused on body weight, but other growth traits which can be affected by compensatory body weight were discussed as well. The threshold numbers reflecting the compensatory like growth degree were also used to analyze other growth traits.

\section{Statistical analysis}

The compensatory index was obtained by the following formulae (Hornick et al., 2000) (Supplementary Fig. S1):

$$
\begin{aligned}
& \text { Index }=(A-B) / A \\
& B W A=B W_{\text {alinel }}-B W_{\text {aline2 }} \\
& B W B=B W_{\text {hlinel }}-B W_{\text {hline2 }}
\end{aligned}
$$

Where, $B W A$ and $B W B$ represent body weight at tagging and harvesting, respectively, lines 1 and 2 are regarded as two parts of a combination dyad, both $A$ and $B$ present the absolute value of growth performance difference in its own growth stage.

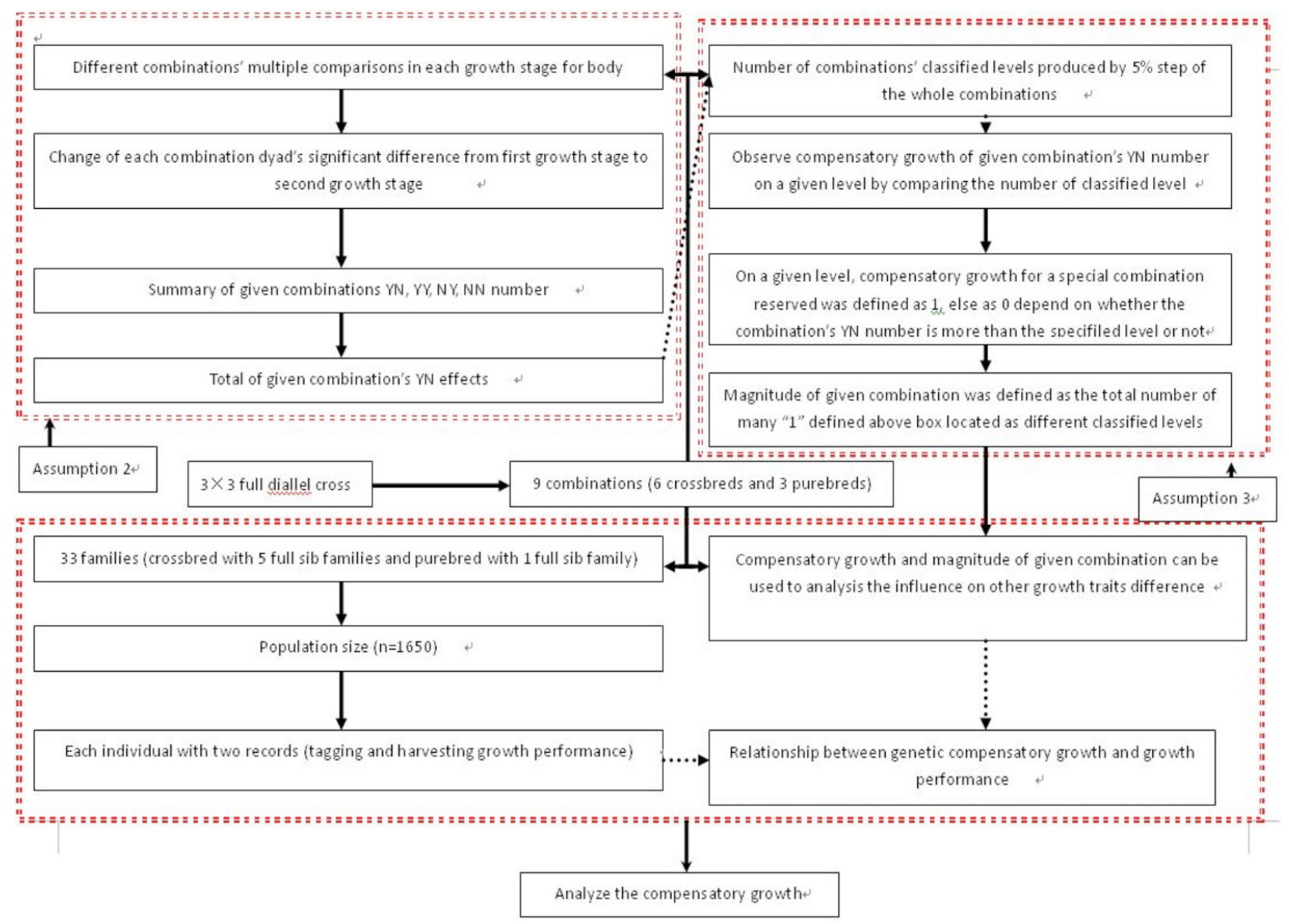

Fig. 1. Compensatory growth analysis method used in the present study. 
Table I.- Compensatory growth indices of each genetic combination.

\begin{tabular}{|c|c|c|c|c|c|c|c|c|}
\hline & Hh & $\mathbf{H j}$ & Hy & Jh & $\mathbf{J j}$ & $\mathbf{J y}$ & Yh & $\mathbf{Y j}$ \\
\hline \multicolumn{9}{|l|}{$\mathrm{Hh}$} \\
\hline $\mathrm{Hj}$ & -33.96 & & & & & & & \\
\hline Нy & -5.54 & -26.03 & & & & & & \\
\hline $\mathrm{Jh}$ & -16.26 & 0.16 & -102.12 & & & & & \\
\hline $\mathrm{Jj}$ & -13.96 & -2.55 & -80.45 & -1484.43 & & & & \\
\hline Jy & -56.31 & -16.49 & -8.29 & -5.54 & -2.64 & & & \\
\hline $\mathrm{Yh}$ & -84.74 & -14.88 & -0.98 & -7.73 & -5.63 & -13.44 & & \\
\hline $\mathrm{Yj}$ & -10.44 & -0.75 & -2.83 & -0.54 & 0.49 & -0.23 & -4.45 & \\
\hline Yy & -0.08 & -23.60 & -4.48 & -13.43 & -11.53 & -28.14 & -64.54 & -13.09 \\
\hline
\end{tabular}

The value present the compensatory index reported by Hornick et al. (2000). In their formula the body weight difference is calculated by absolutions of the body weight difference for both growth stages, thus the element in the table just means the compensatory growth indice in the dyads other than for each

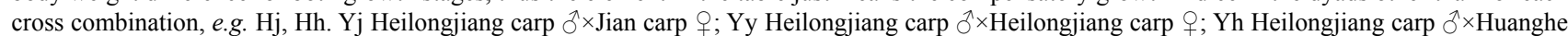

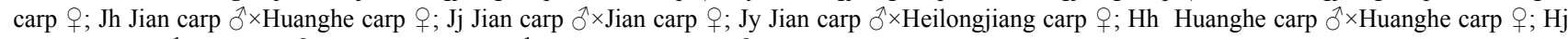

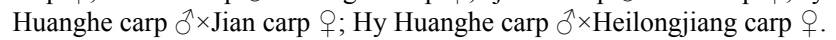

A matrix of the $\mathrm{YN}$ responses was constructed as follows. First, two multiple comparison matrices among different crosses were built in which body weight at tagging and harvesting was defined as dependent variables and fish families as independent variables. Second, specific combination dyads for which significant differences in body weight at tagging were measured but no difference in body weight at harvesting were detected. Then, the number of compensatory degrees for each cross combination (total numbers of yes/no responses) was transformed into 0's and 1's as described above, resulting in a matrix of 0 and 1. Finally, body weights at tagging and harvesting were classified by the 0,1 matrix.

In addition, the following formula was used to calculate body weight gain:

$$
\text { Body weight gain }=B W_{h}-B W_{a}
$$

The results are shown as mean values (SE) for each cross combination. All data were tested with a general linear model using SAS 8.0 software. 3D images for body shape which is described by body length, body width and body height and very import for common carp's market values were also explored using SAS 8.0.

\section{RESULTS}

Growth performance and compensatory indices of each cross combination

Combination Hy had the lowest body weight and the smallest body weight gain at harvesting time, while it had the higher body weight at the tagging time. Combination Jy had the lowest body weight at tagging and the highest body weight at harvesting. Compensatory indices for each cross combination are in Table I. Based on this information, the compensatory index distribution was obtained (Table II). Compensatory indices less than -1 accounted for the biggest proportion of all combination dyads (82\%) while those above 1 accounted for the smallest percentage, which represented the fish with the largest compensatory like growth.

Table II.- Compensatory indices of body weight for different genetic combinations.

\begin{tabular}{|c|c|c|c|c|}
\hline Combination & $<-1$ & Ratio(\%) & {$[-1,1]$} & Ratio(\%) \\
\hline $\mathrm{Hh}$ & 7 & 87.5 & 1 & 12.5 \\
\hline $\mathrm{Hj}$ & 6 & 75 & 2 & 25 \\
\hline Hy & 7 & 87.5 & 1 & 12.5 \\
\hline $\mathrm{Jh}$ & 6 & 75 & 2 & 25 \\
\hline $\mathrm{Jj}$ & 7 & 87.5 & 1 & 12.5 \\
\hline Jy & 7 & 87.5 & 1 & 12.5 \\
\hline $\mathrm{Yh}$ & 7 & 87.5 & 1 & 12.5 \\
\hline $\mathrm{Yj}$ & 4 & 50 & 4 & 50 \\
\hline Yy & 7 & 87.5 & 1 & 12.5 \\
\hline Sum & \multicolumn{2}{|r|}{59} & \multicolumn{2}{|r|}{13} \\
\hline Total & \multicolumn{2}{|r|}{72} & \multicolumn{2}{|r|}{72} \\
\hline Ratio(\%) & \multicolumn{2}{|r|}{81.9} & \multicolumn{2}{|r|}{18.0} \\
\hline
\end{tabular}

' $<-1$ ' present the lower value of compensatory index related with the specified cross combination than -1 ; ' $[-1,1]$ ' is similar to " $<-1$ '. Yj Heilongjiang carp $\hat{\delta} \times$ Jian carp $\odot$; Yy Heilongjiang carp $\hat{\delta} \times$ Heilongjiang carp $\bigcirc$; Yh Heilongjiang carp $\widehat{\partial} \times$ Huanghe carp $\odot$; Jh Jian carp $\hat{\delta} \times$ Huanghe carp $q$; Jj Jian carp $\widehat{\delta} \times$ Jian carp $\odot$; Jy Jian carp $\widehat{\partial} \times$ Heilongjiang carp $Q$; Hh Huanghe carp $\delta \times$ Huanghe carp $\odot$; Hj Huanghe carp $\delta \times$ Jian carp $\odot$; Hy Huanghe carp $\precsim \times$ Heilongjiang carp $\circ$. 
In the present test, the threshold, the maximized ratio achieved by number of observed yes/no responses, is $35 \%$ (Supplementary Table S1). Among the 36 combination dyads, 7 (19.4\%) had yes/no response numbers. Combination $\mathrm{Yj}$ had the largest compensatory like growth and Yy showed no catch-up like growth. After establishing the gradient classified levels, their related compensatory effect on body weight was also examined (Table III). In the $25 \%$ and $35 \%$ levels, the compensatory like growth effect on body weight at tagging was observed, and in the $10 \%$ and $35 \%$ levels, significant differences of harvesting weight and body weight gain were observed.

The maximum ratio (threshold number) of the added yes/no responses was different among all cross combination. These numbers reflect the group's compensatory like growth degree (Table IV). The results showed that, all cross combinations had the highest body weight at the time of tagging in both $10 \%$ and $25 \%$ levels. Significant differences were found between non-compensatory like growth and the whole classified variables on harvesting weight and weight gain and the biggest compensatory like growth effect was observed in the $35 \%$ level.

Table III.- Body weight of all genetic combinations at different classified levels.

\begin{tabular}{lllll}
\hline Level $^{1}$ & $\begin{array}{l}\text { Catch- } \\
\text { up } \\
\text { growth }\end{array}$ & $\begin{array}{l}\text { Tagging } \\
\text { weight (g) }\end{array}$ & $\begin{array}{l}\text { Harvesting } \\
\text { weight (g) }\end{array}$ & $\begin{array}{l}\text { Body weight } \\
\text { gain (g) }\end{array}$ \\
\hline $10 \%$ & 0 & $8.3 \pm 1.02$ & $236.78 \pm 11.15^{\mathrm{b}}$ & $228.48 \pm 10.75^{\mathrm{b}}$ \\
& 1 & $10.23 \pm 0.19$ & $289.17 \pm 2.06^{\mathrm{a}}$ & $278.95 \pm 1.98^{\mathrm{a}}$ \\
$25 \%$ & 0 & $10.90 \pm 0.31^{\mathrm{a}}$ & $283.74 \pm 3.42$ & $272.84 \pm 3.29$ \\
& 1 & $9.76 \pm 0.23^{\mathrm{b}}$ & $289.48 \pm 2.53$ & $279.72 \pm 2.44$ \\
$35 \%$ & 0 & $11.27 \pm 0.19^{\mathrm{a}}$ & $285.67 \pm 2.21^{\mathrm{b}}$ & $274.39 \pm 2.12^{\mathrm{b}}$ \\
& 1 & $4.00 \pm 0.45^{\mathrm{b}}$ & $297.36 \pm 5.20^{\mathrm{a}}$ & $293.36 \pm 5.00^{\mathrm{a}}$ \\
\hline
\end{tabular}

1, each level; different superscript letters (a and b) represent significant differences on specified growth performance at a given level $(P<0.05)$.

Table IV.- Body weight of all genetic combinations at specified classified levels.

\begin{tabular}{llll}
\hline Level $^{\mathbf{1}}$ & $\begin{array}{l}\text { Tagging } \\
\text { weight (g) }\end{array}$ & $\begin{array}{l}\text { Harvesting } \\
\text { weight (g) }\end{array}$ & $\begin{array}{l}\text { Body weight } \\
\text { gain (g) }\end{array}$ \\
\hline 0 & $8.30 \pm 0.96^{\mathrm{b}}$ & $236.78 \pm 11.15^{\mathrm{b}}$ & $228.48 \pm 10.72^{\mathrm{c}}$ \\
$10 \%$ & $11.17 \pm 0.31^{\mathrm{a}}$ & $288.56 \pm 3.57^{\mathrm{a}}$ & $277.39 \pm 3.44^{\mathrm{b}}$ \\
$25 \%$ & $11.54 \pm 0.25^{\mathrm{a}}$ & $287.04 \pm 2.88^{\mathrm{a}}$ & $275.51 \pm 2.77^{\mathrm{b}}$ \\
$35 \%$ & $4.00 \pm 0.45^{\mathrm{c}}$ & $297.36 \pm 5.18^{\mathrm{a}}$ & $293.36 \pm 4.98^{\mathrm{a}}$ \\
\hline
\end{tabular}

1, same to Table III. By sum up the ' 1 ' and ' 0 ' for each cross combination, we can have a new variable, which can determine the maximized compensatory growth magnitude. Compared to Table II focused on the given classified level for whole combinations, Table III focused on the given combination's compensatory growth magnitude.
Compensatory body weight effects on other growth traits

Supplementary Table S2 showed the compensatory body weight effects on body length, body width and body depth obtained from different classified levels. No significant difference in body length at tagging was observed in the $10 \%$ level, whereas a significant difference in body length at harvesting was found. In the $25 \%$ and $30 \%$ levels, body length was the smallest while the highest gain in body length was observed in compensatory like growth individuals. Similar results were also observed for body width and body depth and no developmental malinformation of fishes were found.

In the $30 \%$ level, common carp had the highest harvesting body length and body length gain in the compensatory like growth individuals, but the lowest tagging length as compared to non-compensatory individuals (Table V). Furthermore, body length gain in the $30 \%$ level was higher than in the $10 \%$ and $25 \%$ levels. Similar results were also observed for body depth and body width.

\section{Summary of compensatory like growth effects on different} cross combinations

No compensatory like growth was found for combination $\mathrm{Yy}$, while $\mathrm{Yj}$ had the largest compensatory like growth. The degree of compensatory like growth varied between crosses and reciprocal crosses (Fig. 2).

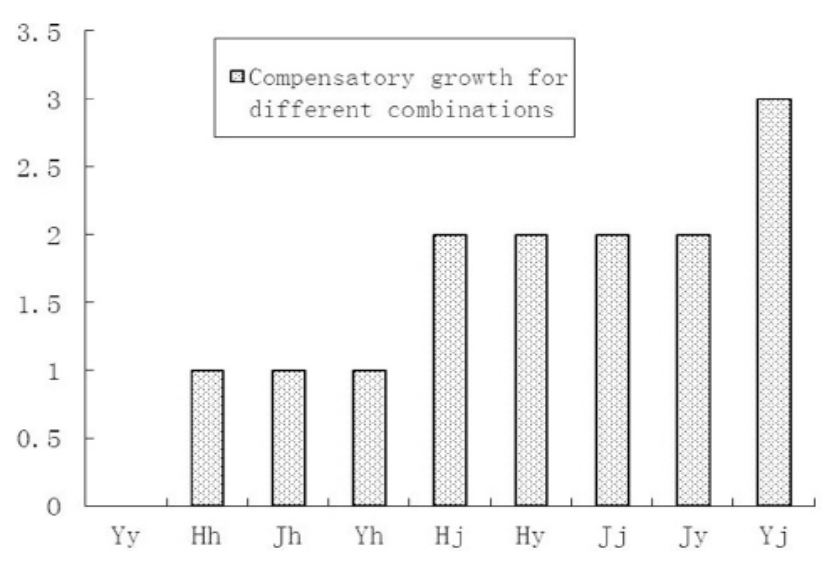

Fig. 2. Magnitude of compensatory growth for different cross combinations. There are four gradient compensatory growth levels of the 9 combinations. Of them, Yy had no compensatory growth while the $\mathrm{Yj}$ had the biggest compensatory growth. Yj Heilongjiang carp $\delta \times$ Jian carp $\bigcirc$; Yy Heilongjiang carp $\hat{\delta} \times$ Heilongjiang carp o; Yh Heilongjiang carp $\hat{\delta} \times$ Huanghe carp $q$; Jh Jian carp $\hat{\delta} \times$ Huanghe carp + ; Jj Jian carp $\hat{\delta} \times$ Jian carp $ᄋ$; Jy Jian carp $\delta^{\lambda} \times$ Heilongjiang carp $\odot$; Hh Huanghe carp $\hat{\partial} \times$ Huanghe carp $\odot$; Hj Huanghe carp $\hat{\delta} \times$ Jian carp $\odot$; Hy Huanghe carp $\hat{\delta} \times$ Heilongjiang carp + . 
Table V.- Body weight of all genetic combinations at specified classified levels.

\begin{tabular}{|c|c|c|c|c|c|c|c|c|}
\hline & Hh & $\mathbf{H j}$ & Hy & $\mathbf{J h}$ & $\mathbf{J j}$ & $\mathbf{J y}$ & $\mathbf{Y h}$ & $\mathbf{Y j}$ \\
\hline \multicolumn{9}{|l|}{$\mathrm{Hh}$} \\
\hline $\mathrm{Hj}$ & -33.96 & & & & & & & \\
\hline Hy & -5.54 & -26.03 & & & & & & \\
\hline $\mathrm{Jh}$ & -16.26 & 0.16 & -102.12 & & & & & \\
\hline $\mathrm{Jj}$ & -13.96 & -2.55 & -80.45 & -1484.43 & & & & \\
\hline Jy & -56.31 & -16.49 & -8.29 & -5.54 & -2.64 & & & \\
\hline Yh & -84.74 & -14.88 & -0.98 & -7.73 & -5.63 & -13.44 & & \\
\hline$Y j$ & -10.44 & -0.75 & -2.83 & -0.54 & 0.49 & -0.23 & -4.45 & \\
\hline Yy & -0.08 & -23.60 & -4.48 & -13.43 & -11.53 & -28.14 & -64.54 & -13.09 \\
\hline
\end{tabular}

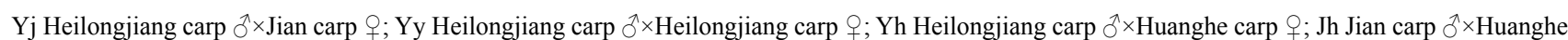

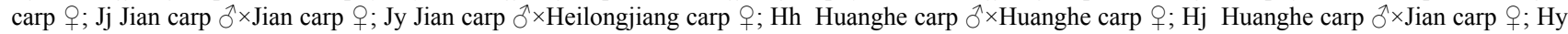
Huanghe carp $\hat{\jmath}^{\times} \times$Heilongjiang carp $q$

The values of body length/body depth were lower in the compensatory than non-compensatory group (Supplementary Fig. S2). For such traits gains, the values at $30 \%$ level were higher than that at $10 \%$ and $25 \%$ levels. However, no significant difference was found between the $10 \%$ and $25 \%$ levels for each trait.

Body shape changed in both two growth phases. The proportion of compensatory individuals (blue proportion in Supplementary Fig. S3) entering the second growth phase varied with the different classified levels and in the second growth phase, body shape for different compensatory degrees varied with catch-up like growth and in noncompensatory individuals (Supplementary Fig. S3).

\section{DISCUSSION}

\section{Compensatory growth in fish}

Compensatory growth in fish is not only of theoretical interest, but also has applications in the design of feeding schedules that improve growth rates and reduce costs (Chaoui et al., 2006; Bavčević et al., 2010; Khan and Abidi, 2010). For common carp, the daily dietary need accounts for $6 \%$ of the body weight (Desai and Singh, 2009). Various restriction factors have been used such as level of nutrients (Nicieza and Álvarez, 2009), low temperatures (Wilson and Osbourn, 1960; Nicieza and Metcalfe, 1997; Ali et al., 2000; Purchase and Brown, 2001), hypoxic conditions (Foss and Imsland, 2002), salinity level (Damsgard and Arnesen, 1998), prophylactic treatment (Speare and Arsenault, 1997), endocrine reactions (Montserrat et al., 2007) and density alternation (Basiao et al., 1996). Besides body weight, the effect of compensatory growth was investigated on many other traits such as carcass components, feed efficiency and behavior (Kabbali et al.,
1992; Dmitriew and Rowe, 2007). For example, Wang et al. (2000) examined the effect of compensatory growth on protein, lipid and gray matter levels as well as body weight and found that only body weight was affected. Chaosap et al. (2011) reported that body weight gain and intramuscular fat were influenced by compensatory growth. However, these compensatory growth effects are also related with environmental factors (Turano et al., 2008).

Growth performance improvement of Common carp as a major species in Chinese aquaculture production has been widely concerned. Of them, cross-breeding between various strains is an efficient approach to improve the performance of growth rate in this species (Bakes and Gorda, 1995; Linhart et al., 2002; Su et al., 2011). In the last years, this approach was carried on the three main Chinese common carp strains (i.e. Jian carp, Huanghe carp and Heilongjiang carp) and initiated a $3 \times 3$ full diallel cross between these strains and finally produced six crossbreds and three purebreds (Su et al., 2012). The results showed that, some cross combinations reached the highest body weight during the first growth phase but lost this advantage in the second growth phase ( $\mathrm{Su}$ et al., 2012), which suggested the existence of a genetic-based compensatory like growth mechanism. Moreover, in the recent years, global gene expression patterns and genes required in compensatory growth caused by genetic mechanism have been determined and identified separately (He et al., 2015; Gerhold et al., 2011). In order to evaluate the possible benefits of compensatory like growth in cross breeding, it is necessary to understand the dynamics change underlying this genetic trait. In this study, we present an experiment that analyzed the effects of compensatory like growth on body weight and other growth traits in a $3 \times 3$ full diallel cross between three common carp strains $(\mathrm{Su}$ 
et al., 2011). In addition, the relationships between groups of fish with a given cross combination and compensatory like growth were determined using defined $\mathrm{Y} / \mathrm{N}$ effect and compensatory like growth degree method.

Compensatory like growth of common carp by genetic background and its magnitude measurement

In the diallel cross tests, the profile of changes in body weight varied among the different combinations (Su et al., 2012), although the whole extra condition keep the same with each other. Therefore, the differences may have been caused by compensatory mechanism. Based on the compensatory index matrix of the 72 combination dyads, there was a large percentage $(82 \%)$ of fish had the compensatory indices values below -1 , which means that almost all the groups from the second growth phase (between tagging and harvesting) had more than a twofold growth gap compared to those from the first growth phase (between spawning and tagging). The distribution of compensatory indices can reflect the level of compensatory like growth response between groups but it cannot estimate the catch-up like growth performance of each group.

In this study, the YN response was introduced to evaluate the magnitude of compensatory like growth for a given cross combination. The higher the value of the added yes/no responses represented, the higher the compensatory like growth capacity had. In order to classify the whole population into gradient groups, levels of percentages were introduced as thresholds, which revealed the highest percentage of individuals when comparing the value of the accumulated yes/no responses cross combination among 8 combination dyads for each cross combination. Reciprocal cross-breeding with a given strain can influence compensatory like growth, for example, a cross between Jian carp as maternal parent and Huanghe carp as paternal parent shows an increase in compensatory like growth performance. Similarly, Fraser et al. (2007) found genetically-based salmon population differences in compensatory growth responses. In Table V, the differences of tagging weight were so big comparing level $35 \%$ to level $10 \%$ and $25 \%$, but the $35 \%$ levels had highest harvesting weight and body weight gain. This may be caused by magnitude of compensatory like growth, e.g. no significant harvesting weight and body weight gain between $10 \%$ and $25 \%$. During the breeding process, compensatory like growth can be considered as a growth pattern trait that is genetically transmitted (Koskimäki et al., 1979) and caused by selection (Fraser et al., 2007). Marks verified this relationship between specie selection and compensatory growth (Marks, 1979).

In this study, individuals (except at the $10 \%$ level) had a lower weight at tagging presented a catch-up like growth body weight gain at harvest. This confirms the validity of the yes/no response method. Compared to a population without compensatory like growth, the population with the lowest compensatory like growth rate had the highest performance in body length, body depth and body width and exaggerated harvesting performance and performance gain. This advantage became smaller as the compensatory level increased. With 3D images, compensatory like growth magnitudes were developed from single growth trait to three traits together. It is interesting that several reports have shown that traits related to disease resistance are involved in the variation of growth rate during an animal's lifetime (Tuckey et al., 2002; Emhart et al., 2006). In order to explore the genetic mechanism of compensatory like growth, genes, such as Ribonucleoside diphosphate reductase large subunit ( $\mathrm{RnrL}$ ) required in extensive damage caused-organs compensatory like growth has been identified (Gerhold et al., 2011). A possible mechanistic link between nutritionally induced compensatory like growth, epigenetic control of mammary gene expression and metabolic imprinting was inferred (Park, 2005).

The novel method tried to provide new insight on compensatory like growth, because it is considered to be transmitted genetically, although it is generally accepted that compensatory growth was influenced by nutritional restrictions and environmental conditions. The question of whether genetic factors participate in catch-up like growth is a new issue. Therefore, new reports on different species on this issue are encouraged. If this is true, there should be a possible way to produce new strains with improved compensatory like growth performance and to select specific broodstocks adapted to restricted environment or nutrition factors in future.

\section{CONCLUSION}

Compensatory index matrix was constructed to investigate compensatory like growth in full diallel crossing combinations. The yes/no response was useful in evaluating the degree of catch-up like growth. This new method was tested to analyze the compensatory like growth of common carp in different cross combinations at these two different growth phases. The results showed that compensatory like growth was affected by genetic restriction factors. In perspective, analysis of compensatory like growth may be included in selective breeding programs.

\section{ACKNOWLEDGMENTS}

This work was supported by grants from the Key Projects in the National Science and Technology Pillar 
Program during the twelfth Five-Year Plan Period (2012BAD26B02), the Chinese Earmarked Fund for Modern Agro-Industry Technology Research System (CARS-46) and the National Nonprofit Institute Research Grant of CATAS-TCGRI (2013JBFM14). The authors thank the students and staff of Aquatic Genetic Laboratory, FFRC for their kind assistance in the study.

\section{Supplementary material}

There is supplementary material associated with this article. Access the material online at: http://dx.doi. org/10.17582/journal.pjz/2017.49.6.2123.2131

\section{Statement of conflict of interest}

Authors have declared no conflict of interest.

\section{REFERENCES}

Ali, M., Nicieza, A. and Wootton, R.J., 2000. Compensatory growth in fishes: a response to growth depression. Fish Fish., 4: 147-190. https:// doi.org/10.1046/j.1467-2979.2003.00120.x

Bakes, J. and Gorda, S., 1995. Genetic improvement of common carp strains using intraspecific hybridization. Aquaculture, 129: 183-186. https:// doi.org/10.1016/0044-8486(94)00245-J

Balon, E.K., 1995. Origin and domestication of the wild carp, Cyprinus carpio: from Roman gourmets to the swimming flowers. Aquaculture, 129: 3-48. https://doi.org/10.1016/0044-8486(94)00227-F

Basiao, Z.U., Doyle, R.W. and Arago, A.L., 1996. A statistical power analysis of the 'internal reference' technique for comparing growth and growth depensation of tilapia strains. J. Fish Biol., 49: 277 286. https://doi.org/10.1111/j.1095-8649.1996. tb00023.x

Bavčević, L., Klanjšček, T., Karamarko, V., Aničić, I. and Legovi, T., 2010. Compensatory growth in gilthead sea bream (Sparus aurata) compensates weight, but not length. Aquaculture., 301: 57-63. https://doi.org/10.1016/j.aquaculture.2010.01.009

Chaoui, L., Hicem, K.M., Faure, E. and Quignard, J.P., 2006. Growth and reproduction of the Gilthead Sea bream Sparus auratain Mellah lagoon (NorthEastern Algeria). Sci. Mar., 70: 546-552. https:// doi.org/10.3989/scimar.2006.70n3545

Chaosap, C., Parr, T. and Wiseman, J., 2011. Effect of compensatory growth on performance, carcass composition and plasma IGF-1 in grower finisher pigs. Animal, 5: 749-756. https://doi.org/10.1017/ S1751731110002399

Damsgard, B. and Arnesen, A.M., 1998. Feeding, growth and social interactions during smolting and seawater acclimation in Atlantic salmon, Salmosalar L. Aquaculture, 168: 7-16. https://doi. org/10.1016/S0044-8486(98)00335-4

Dmitriew, C. and Rowe, L., 2007. Effects of early resource limitation and compensatory growth on lifetime fitness in the lady bird beetle (Harmonia axyridis). J. Evolut. Biol., 20: 1298-1310. https:// doi.org/10.1111/j.1420-9101.2007.01349.x

Desai, A.S. and Singh, P.K., 2009. The effects of water temperature and ration size on growth and body composition of larvae of common carp, Cyprinus carpio L. J. theor. Biol., 34: 276-280. https://doi. org/10.1016/j.jtherbio.2009.03.005

Emhart, V.I., Martin, T.A., White, T.L. and Huber, D.A., 2006. Genetic variation in basal area increment phenology and its correlation with growth rate in loblolly and slash pine families and clones. Can. J. Forest Res., 36: 961-971. https://doi.org/10.1139/ x05-309

Foss, A. and Imsland, A.K., 2002. Compensatory growth in the spotted wolfish Anarhichas minor (Olafsen) after a period of limited oxygen supply. Aquacult. Res., 33: 1097-1101. https://doi.org/10.1046/ j.1365-2109.2002.00768.x

Fraser, D.J., Weir, L.K., Darwish, T.L., Eddington, J.D. and Hutchings, J.A., 2007. Divergent compensatory growth responses within species: linked to contrasting migrations in salmon? Oecologia, 153: 543-553. https://doi.org/10.1007/s00442-0070763-6

Gerhold. A.R., Richter. D.J., Yu, A.S. and Hariharan, I.K., 2011. Identification and characterization of genes required for compensatory growth in Drosophila. Genetics, 189: 1309-1326. https://doi. org/10.1534/genetics.111.132993

He, L.B., Pei, Y.Y., Jiang, Y., Li, Y.M., Liao, L.J., Zhu, Z.Y. and Wang, Y.W., 2015. Global gene expression patterns of grass carp following compensatory growth. BMC Genom., 16: 184 . https://doi. org/10.1186/s12864-015-1427-2

Hornick, J.L., Van Eenaeme, C., Gerard, O., Dufrasne, I. and Istasse, L., 2000. Mechanisms of reduced and compensatory growth. Domest. Anim. Endocri., 19: 121-132. https://doi.org/10.1016/S07397240(00)00072-2

Khan, M.A. and Abidi, S.F., 2010. Optimum ration level for better growth, conversion efficiencies and body composition of fingerling Heteropneustes fossilis (Bloch). Aquacult. Int., 18: 175-188. https://doi. org/10.1007/s10499-008-9234-2

Koskimäki, A., Hari, P., Kellomäki, S. and Kanninen, 
M., 1979. Inherent growth rhythm of some larixspecies grown in a plastic greenhouse. Silva. Fenn., 13: 108-114. https://doi.org/10.14214/sf.a14875

Kabbali, A., Johnson, W.L., Johnson, D.W., Goodrich, R.D. and Allen, C.E., 1992. Effects of compensatory growth on some body component weights and on carcass and noncarcass composition of growing lambs. J. Anim. Sci., 70: 2852-2858. https://doi. org/10.2527/1992.7092852x

Linhart, O., Gela, D., Rodina, M., Slechtova, V. and Slechta, V., 2002. Top-crossing with paternal inheritance testing of common carp (Cyprinus carpio L.) progeny under two altitude conditions. Aquaculture, 204: 481-491. https://doi.org/10.1016/ S0044-8486(01)00833-X

Lippens, M., Huyghebaert, G. and de Groote, G., 2002. The efficiency of nitrogen retention during compensatory growth of food-restricted broilers. Br. Poult. Sci., 43: 669-676. https://doi. org/10.1080/0007166022000025055

Marks, H.L., 1979. Compensatory growth of selected and non-selected broilers following early protein restriction. Poult. Sci., 58: 1409-1414. https://doi. org/10.3382/ps.0581409

Montserrat, N., Gabillard, J.C., Capilla, E., Navarro, M.I. and Gutiérrez, J., 2007. Role of insulin, insulin-like growth factors, and muscle regulatory factors in the compensatory growth of the trout (Oncorhynchus mykiss). Gen. Comp. Endocr., 150: 462-472. https://doi.org/10.1016/j.ygcen.2006.11.009

Nicieza, A.G. and Metcalfe, N.B., 1997. Growth compensation in juvenile Atlantic salmon: responses to depressed temperature and food availability. Ecology, 78: 2385-2400. https://doi. org/10.1890/0012-9658(1997)078[2385:GCIJAS] 2.0.CO;2

Nicieza, A. and Álvarez, D., 2009. Statistical analysis of structural compensatory growth: how can we reduce the rate of false detection? Oecologia, 59: 27-39. https://doi.org/10.1007/s00442-008-1194-8

Park, C.S., 2005. Role of compensatory mammary growth in epigenetic control of gene expression. FASEB. J., 19:1586-1591. https://doi.org/10.1096/ fj.05-3816hyp

Purchase, C.F. and Brown, J.A., 2001. Stock specific changes in growthrates, food conversionefficiencies, and energy allocation in response to temperature change in juvenile Atlantic cod. J. Fish Biol., 58:
36-52. https://doi.org/10.1111/j.1095-8649.2001. tb00497.x

Ryan, W.J., 1990. Compensatory growth in cattle and sheep. Nutr. Abstr. Rev., 60: 653-664.

Speare, D.J. and Arsenault, G.J., 1997. Effects of intermittent hydrogen peroxide exposure on growth and columnaris disease prevention of juvenile rainbow trout (Oncorhynchus mykiss). Can. J. Fish. aquat. Sci., 54: 2653-2658. https://doi.org/10.1139/ f97-169

Su, S.Y., Dong, Z.J., Qu, J.Q., Liang, Z.Y., Zhang, J.Q., Liu, W. and Ma, L.X., 2011. Grey correlated degree analysis of growth trait of hybrids from 3 common carp varieties and prediction on body weight of offspring from multiple crosses. J. Fish. Sci. China, 35: 20-26.

Su, S.Y., Dong, Z.J., Zhang, C.F., Yuan, X.H., Xu, P., Ma, Q.N., Liang, Z.Y., Qu, J.Q., Zhang, J.Q., Liu, W. and Ma, L.X., 2012. Characters of different growth stage on the $\mathrm{fl}$ progeny of $3 \times 3$ full diallel cross in common carp (Cyprinus carpio L.). Acta Hydrobiol. Sin., 36: 1-8.

Tuckey, D.M., Orcutt, D.M. and Hipkins, P.L., 2002. Inherent and growth stage-related differences in growth and lipid and sterol composition of algal species sensitive and tolerant to sterol inhibiting fungicides. Environ. Toxicol. Chem., 21: 1715-1723. https://doi.org/10.1897/15515028(2002)021<1715:IAGSRD>2.0.CO;2

Turano, M.J., Borski, R.J. and Daniels, H.V., 2008. Effects of cyclic feeding on compensatory growth of hybrid striped bass (Morone chrysops $\times M$. saxitilis) foodfish and water quality in production ponds. Aquacult. Res., 39: 1514-1523. https://doi. org/10.1111/j.1365-2109.2008.02023.x

Velisek, J., Svobodova, Z., Piackova, V., Groch, L. and Nepejchalova, L., 2005. Effects of clove oil anaesthesia on common carp (Cyprinus carpio L.). Vet. Med., 50: 269-275.

Wilson, P.N. and Osbourn, D.F., 1960. Compensatory growth after undernutrition in mammals and birds. Biol. Rev., 35: 324-363. https://doi.org/10.1111/ j.1469-185X.1960.tb01327.x

Wang, Y., Cui, Y.B., Yang, Y.X. and Cai, F.S., 2000. Compensatory growth in hybrid tilapia, Oreochromis mossambicus $\times$ O. niloticus reared in seawater. Aquaculture, 189: 101-108. https://doi. org/10.1016/S0044-8486(00)00353-7 